\title{
E3 Ubiquitin-Protein Ligase TRIM13
}

National Cancer Institute

\section{Source}

National Cancer Institute. E3 Ubiquitin-Protein Ligase TRIM13. NCI Thesaurus. Code C29838.

E3 ubiquitin-protein ligase TRIM13 (407 aa, $47 \mathrm{kDa}$ ) is encoded by the human TRIM13 gene. This protein plays a role in regulating the degradation of endoplasmic reticulum proteins. 